\title{
Determination of ATP as a Fluorescence Probe with Europium(III)-Doxycycline
}

\author{
Faju Hou, Xiaolei Wang, and Chongqiu JIANG ${ }^{\dagger}$ \\ Department of Chemistry, Shandong Normal University, Jinan, 250014, China
}

\begin{abstract}
A new spectrofluorimetric method has been developed for the determination of adenosine disodium triphosphate (ATP). We studied the interactions between the doxycycline (DC)-E $\mathbf{u}^{3+}$ complex and adenosine disodium triphosphate (ATP) by using UV-visible absorption and fluorescence spectra. Using doxycycline (DC)-Eu ${ }^{3+}$ as a fluorescence probe, under the optimum conditions, ATP could remarkably enhance the fluorescence intensity of the DC-Eu ${ }^{3+}$ complex at $\lambda=612 \mathrm{~nm}$. The enhanced fluorescence intensity of the $\mathrm{Eu}^{3+}$ ion was in proportion to the concentration of ATP. The optimum conditions for the determination of ATP were also investigated. The linear ranges for ATP were $1.00 \times 10^{-7}-2.00 \times 10^{-6}$ mol L ${ }^{-1}$ with detection limits of $4.07 \times 10^{-8} \mathrm{~mol} \mathrm{~L}^{-1}$. This method is simple, practical and relatively free of interference from coexisting substances, and can be successfully applied to the determination of ATP in samples. The mechanism of fluorescence enhancement between the doxycycline (DC)-Eu ${ }^{3+}$ complex and ATP was also studied.
\end{abstract}

(Received August 6, 2004; Accepted October 18, 2004)

\section{Introduction}

Adenosine disodium triphosphate (ATP) is the mediator of energy exchanges that occur in all living cells, both catabolic, degradative processes and anabolic, biosynthesis processes. Because of its ubiquitous presence in living matter, ATP has been widely used as an index for biomass determinations in clinical microbiology, food quality control and environmental analyses. The most commonly used methods for the determination of ATP include the bioluminescent method, ${ }^{1,2}$ chromatography, ${ }^{3}$ biosensor using isolated enzyme, ${ }^{4-6}$ luminescence, ${ }^{7,8}$ HPLC, ${ }^{9,10}$ and enzymatic cycling method. ${ }^{11}$

In the present work we studied the interactions between the doxycycline (DC)-Eu ${ }^{3+}$ complex and adenosine disodium triphosphate (ATP) by using the UV-visible absorption and fluorescence spectra. The doxycycline is one kind of better antibiotic pharmaceuticals; its antibacterial spectrum is the same as that of tetracycline, but its curative effect is superior to that of chlortetracycline and tetracycline. Doxycycline (DC) containing $\beta$-diketonate configuration is a good ligand for $\mathrm{Eu}^{3+}$, and can strongly bind with $\mathrm{Eu}^{3+}$. In this work, we selected DC as a ligand of the $\mathrm{Eu}^{3+}$ ion, and investigated the possibility of enhancing the $\mathrm{Eu}^{3+}$ ion sensitized fluorescence by ATP. The experimental results indicate that the characteristic peak of the $\mathrm{Eu}^{3+}$ ion at $612 \mathrm{~nm}$ can be greatly enhanced in the $\mathrm{DC}-\mathrm{Eu}^{3+}$ system by ATP, and that the enhancement comes from the intramolecular energy transfer in the DC-ATP-Eu ${ }^{3+}$ ion ternary complex in close proximity. Accordingly, a new fluorescence method with high sensitivity and selectivity has been established for the determination of ATP.

\footnotetext{
† To whom correspondence should be addressed.

E-mail: jiangchongqiu@sdnu.edu.cn
}

\section{Experimental}

\section{Apparatus}

All fluorescence measurements were carried out on an RF-540 recording spectrofluorimeter (Shimadzu, Kyoto, Japan). A UV265 recording spectrophotometer (Shimadzu, Kyoto, Japan) was used for UV spectra scanning and determination experiments. All of the $\mathrm{pH}$ measurements were made with a $\mathrm{pHs}-3 \mathrm{C}$ digital pH meter (Shanghai Leici Device Works, China).

\section{Solutions}

All chemicals used were of analytical-reagent or higher grade. Doubly distilled demineralized water was used for the preparation of all solutions and for all determinations.

An adenosine disodium triphosphate (ATP, Shanghai Bio Life Science \& Technology Co., Ltd.) solution was directly dissolved with doubly distilled demineralized water. The working standard solution was freshly prepared by appropriate dilution with doubly distilled demineralized water.

A stock doxycycline (DC, Biological Product Institution of Chinese Medicine) solution was dissolved with a small amount of hydrochloric acid, and then diluted to the mark with doubly distilled demineralized water. The working standard solution was freshly prepared by appropriate dilution with doubly distilled demineralized water.

A Eu ${ }^{3+}$ ion stock solution was prepared by dissolving $\mathrm{Eu}_{2} \mathrm{O}_{3}$ (more than 99.99\%, Shanghai Yuelong Chemical Plant, China) with a small amount of hydrochloric acid, and then diluted to the mark with hydrochloric acid $\left(0.1 \mathrm{~mol} \mathrm{~L}^{-1}\right)$. The working solution was obtained by appropriate dilution of the stock solution with doubly distilled demineralized water.

$\mathrm{NH}_{3}-\mathrm{NH}_{4} \mathrm{Cl}(0.10 \mathrm{~mol} \mathrm{~L}-1, \mathrm{pH}=10.00)$ buffer solution was used. All stocks and working solutions were stored at $0-4^{\circ} \mathrm{C}$.

\section{Experiment procedure}

To $10 \mathrm{ml}$ color comparison tubes, solutions were added in the 

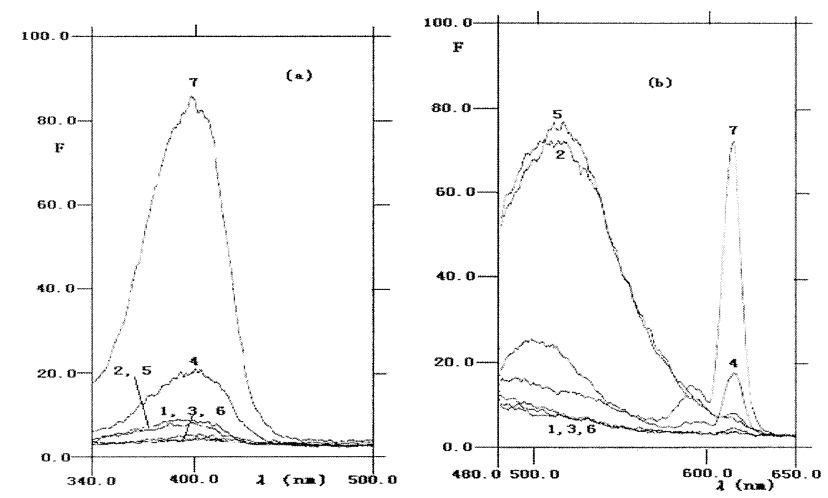

Fig. 1 (a) Fluorescence excitation spectra. (b) Fluorescence emission spectra. 1, $\mathrm{Eu}^{3+} ;$ 2, DC; 3, ATP; 4, DC-Eu ${ }^{3+} ;$ 5, DC-ATP; 6, $\mathrm{Eu}^{3+}$-ATP; 7, DC-Eu ${ }^{3+}$-ATP. Experiment conditions: DC, $3.58 \times 10^{-6}$ $\mathrm{mol} \mathrm{L}{ }^{-1} ; \mathrm{Eu}^{3+}, 6.0 \times 10^{-6} \mathrm{~mol} \mathrm{~L}^{-1}$; ATP, $2.0 \times 10^{-6} \mathrm{~mol} \mathrm{~L}^{-1} ; \mathrm{pH}, 10.00$; $\lambda_{\text {ex }}, 385 \mathrm{~nm} ; \lambda_{\text {em }}, 612 \mathrm{~nm}$.

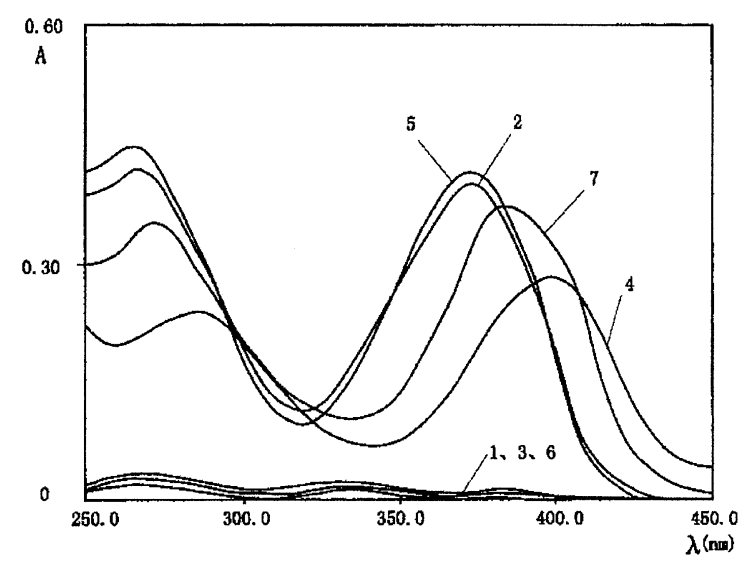

Fig. 2 Absorption spectra. 1, Eu ${ }^{3+} ; 2$, DC; 3, ATP; 4, DC-Eu ${ }^{3+} ; 5$,

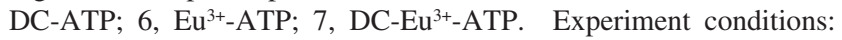
DC, $1.43 \times 10^{-5} \mathrm{~mol} \mathrm{~L}^{-1}$; $\mathrm{Eu}^{3+}, 2.5 \times 10^{-5} \mathrm{~mol} \mathrm{~L}^{-1}$; ATP, $1.0 \times 10^{-5}$ mol L-1.

following order: DC, $\mathrm{Eu}^{3+}$, ATP and buffer solution. Each mixture was diluted to the mark with doubly distilled demineralized water, and left standing for $20 \mathrm{~min}$ at room temperature. The fluorescence intensity was measured at $\lambda_{\text {ex }} / \lambda_{\text {em }}=385 \mathrm{~nm} / 612 \mathrm{~nm}$. The enhanced fluorescence intensity of DC-Eu ${ }^{3+}$ by ATP was represented as $\Delta F=F-F_{0}$. Here, $F$ and $F_{0}$ are the fluorescence intensities of the systems with and without ATP, respectively.

\section{Results and Discussion}

\section{Excitation spectra and emission spectra}

Fluorescence excitation spectra and fluorescence emission spectra of $\mathrm{Eu}^{3+}, \mathrm{DC}, \mathrm{ATP}, \mathrm{ATP}+\mathrm{Eu}^{3+}, \mathrm{DC}+\mathrm{ATP}, \mathrm{DC}+\mathrm{Eu}^{3+}$, $\mathrm{DC}+\mathrm{ATP}+\mathrm{Eu}^{3+}$ are shown in the Fig. 1(a) and Fig. 1(b). Pure $\mathrm{Eu}^{3+}$ does not show the characteristic spectrum of $\mathrm{Eu}^{3+}$, and the characteristic spectrum of $\mathrm{ATP}-\mathrm{Eu}^{3+}$ is not apparent. The characteristic spectrum of DC-Eu ${ }^{3+}$ is shown in Fig. 1 with $\lambda_{\text {ex }}=$ $385 \mathrm{~nm}$ and $\lambda_{\mathrm{em}}=590.0$ and $612.0 \mathrm{~nm}$, corresponding to the ${ }^{5} \mathrm{D}_{0}{ }^{-} \mathrm{F}_{1}$ and ${ }^{5} \mathrm{D}_{0}{ }^{7} \mathrm{~F}_{2}$ transition of $\mathrm{Eu}^{3+}$, respectively. After the addition of ATP into the DC-Eu ${ }^{3+}$ system, a light blue shift occurred to the maximal excitation wavelength, and the

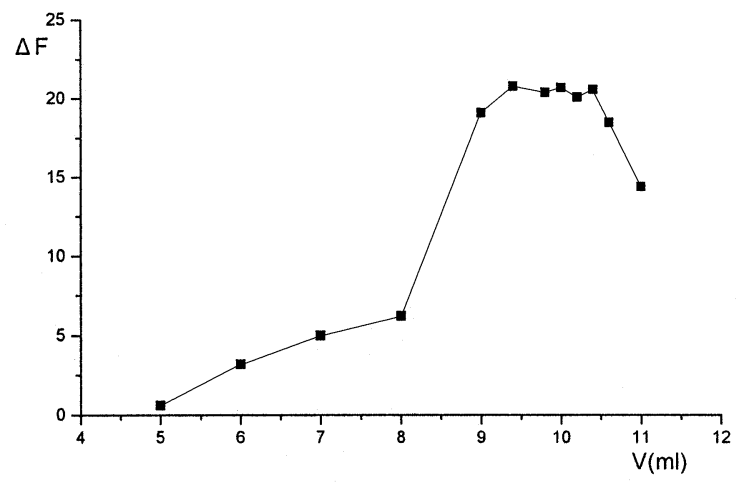

Fig. 3 Influence of the $\mathrm{pH}$ on $\Delta F$.

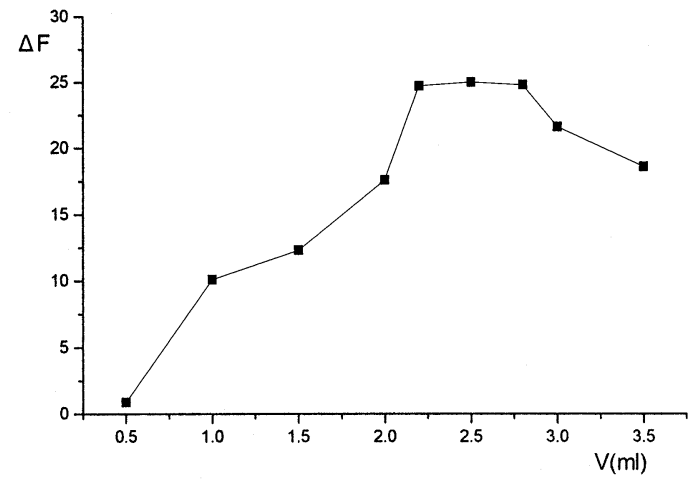

Fig. 4 Influence of the DC concentration on $\Delta F$.

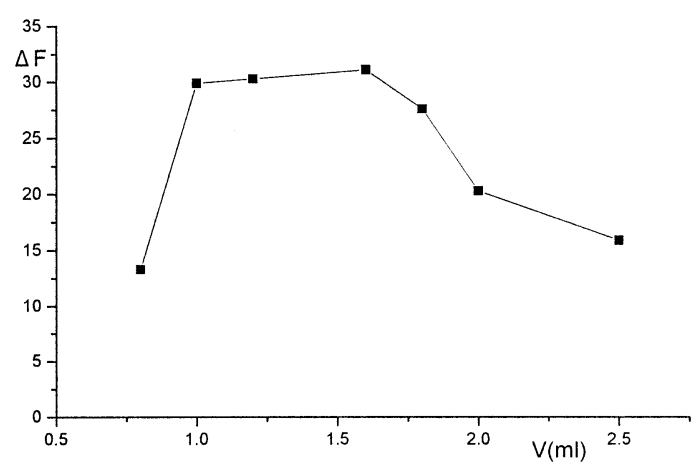

Fig. 5 Influence of the $\mathrm{Eu}^{3+}$ concentration on $\Delta F$.

fluorescence intensity of the $\mathrm{Eu}^{3+}$ ion at $612 \mathrm{~nm}$ could be enhanced remarkably. Therefore, $612 \mathrm{~nm}$ was chosen for the determination of DC.

The absorption spectra of $\mathrm{Eu}^{3+}, \mathrm{DC}, \mathrm{ATP}, \mathrm{ATP}+\mathrm{Eu}^{3+}, \mathrm{DC}+$ $\mathrm{ATP}, \mathrm{DC}+\mathrm{Eu}^{3+}$, and $\mathrm{DC}+\mathrm{ATP}+\mathrm{Eu}^{3+}$ are shown in Fig. 2 . It can be seen that after the addition of ATP into the DC-Eu ${ }^{3+}$ system, a little blue shift occurred to the maximal absorption peak. This resulted from the formation of the DC $+\mathrm{ATP}+\mathrm{Eu}^{3+}$ complex.

Optimization of reaction conditions

Effect of the acidity. The effects of the $\mathrm{pH}$ on the $F$ are shown in Fig. 3. The experimental results showed that $F$ reached the maximum value in the $\mathrm{pH}$ range $9.40-10.40$. We thus selected $\mathrm{pH}=10.00$ of a 0.10 mol L-1 $\mathrm{NH}_{3}-\mathrm{NH}_{4} \mathrm{Cl}$ buffer solution for 
Table 1 Influence of coexisting substances on the $\mathrm{DC}-\mathrm{Eu}^{3+}$ ATP system

\begin{tabular}{|c|c|c|}
\hline Coexisting substance & Concentration $/ \mathrm{mol} \mathrm{L}^{-1}$ & $\Delta F, \%$ \\
\hline $\mathrm{Cu}^{2+}\left(\mathrm{SO}_{4}^{2-}\right)$ & $1.6 \times 10^{-6}$ & 1.5 \\
\hline $\mathrm{Zn}^{2+}\left(\mathrm{SO}_{4}^{2-}\right)$ & $2.4 \times 10^{-6}$ & 0.1 \\
\hline $\mathrm{Fe}^{2+}\left(\mathrm{SO}_{4}{ }^{2-}\right)$ & $1.1 \times 10^{-6}$ & -4.6 \\
\hline $\mathrm{Al}^{3+}\left(\mathrm{SO}_{4}{ }^{2-}\right)$ & $3.8 \times 10^{-6}$ & 3.5 \\
\hline $\mathrm{Mg}^{2+}\left(\mathrm{SO}_{4}{ }^{2-}\right)$ & $1.0 \times 10^{-5}$ & -0.6 \\
\hline $\mathrm{Fe}^{3+}\left(\mathrm{SO}_{4}{ }^{2-}\right)$ & $9.0 \times 10^{-7}$ & 0.8 \\
\hline $\mathrm{Hg}^{2+}\left(\mathrm{Cl}^{-}\right)$ & $2.5 \times 10^{-7}$ & 9.7 \\
\hline $\mathrm{Cd}^{2+}\left(\mathrm{Cl}^{-}\right)$ & $1.8 \times 10^{-6}$ & 3.5 \\
\hline $\mathrm{Co}^{2+}\left(\mathrm{Cl}^{-}\right)$ & $1.0 \times 10^{-6}$ & -9.4 \\
\hline $\mathrm{Mn}^{2+}\left(\mathrm{Cl}^{-}\right)$ & $1.0 \times 10^{-6}$ & 8.2 \\
\hline $\mathrm{Mo}^{6+}\left(\mathrm{Cl}^{-}\right)$ & $1.0 \times 10^{-7}$ & 3.0 \\
\hline $\mathrm{Ca}^{2+}\left(\mathrm{Cl}^{-}\right)$ & $1.0 \times 10^{-6}$ & 7.8 \\
\hline DNA & $4.1 \times 10^{-6}$ & 4.6 \\
\hline HSA & $2.0 \times 10^{-7}$ & 1.5 \\
\hline BSA & $1.0 \times 10^{-7}$ & 2.3 \\
\hline Glucose & $1.0 \times 10^{-3}$ & -4.6 \\
\hline Thymine & $1.9 \times 10^{-6}$ & 9.4 \\
\hline Cytosine & $1.1 \times 10^{-7}$ & 9.3 \\
\hline Guanine & $3.2 \times 10^{-7}$ & 5.3 \\
\hline Adenine & $1.1 \times 10^{-8}$ & 3.4 \\
\hline Trichloroacetic acid & $1.4 \times 10^{-4}$ & -6.7 \\
\hline Lactic acid & $1.7 \times 10^{-4}$ & -5.6 \\
\hline Sucrose & $1.0 \times 10^{-4}$ & -3.4 \\
\hline L-Histidine & $9.9 \times 10^{-6}$ & 8.8 \\
\hline L-Glutamic acid & $2.0 \times 10^{-5}$ & 7.9 \\
\hline L-Lysine & $1.0 \times 10^{-5}$ & -1.8 \\
\hline L-Cystine & $2.0 \times 10^{-5}$ & 7.0 \\
\hline Leucine & $1.0 \times 10^{-5}$ & 6.7 \\
\hline Tyrosine & $1.0 \times 10^{-5}$ & 6.7 \\
\hline Glycin & $1.0 \times 10^{-5}$ & 9.4 \\
\hline Methionine & $1.0 \times 10^{-5}$ & 9.3 \\
\hline Tryptophane & $1.0 \times 10^{-5}$ & 5.3 \\
\hline
\end{tabular}

further study. As the volume of the buffer solution was added from $1.0 \mathrm{ml}$ to $2.5 \mathrm{ml}$, the fluorescence intensity reached the maximum and remained constant. Thus $2.0 \mathrm{ml}$ was used for the following experiments.

Effect of the DC concentration. The effect of the DC concentration on the proportion of $\Delta F$ is shown in Fig. 4. In the system DC-Eu ${ }^{3+}$-ATP, when DC was in the range of $2.2-2.8 \mathrm{ml}$ $\left(3.15 \times 10^{-6} \mathrm{~mol} \mathrm{~L}^{-1}-4.00 \times 10^{-6} \mathrm{~mol} \mathrm{~L}^{-1}\right), \Delta F$ reached the maximum, and remained constant. Thus $2.5 \mathrm{ml}$ was used for further study.

Effect of the Eu ${ }^{3+}$ concentration. The effects of the $\mathrm{Eu}^{3+}$ concentration on $F$ and $\Delta F$ are shown in Fig. 5. In the system DC-Eu${ }^{3+}$-ATP, when $\mathrm{Eu}^{3+}$ was in the range of $1.0-1.6 \mathrm{ml}(5.0 \times$ $\left.10^{-6} \mathrm{~mol} \mathrm{~L}^{-1}-8.0 \times 10^{-6} \mathrm{~mol} \mathrm{~L}^{-1}\right)$, the fluorescence intensity reached the maximum, and remained constant. Thus $1.2 \mathrm{ml}$ was used for further study, and $\mathrm{C}_{\mathrm{DC}}: \mathrm{C}_{\mathrm{Eu}^{3+}}=3: 5$.

Effect of reaction time. The chelation reaction was completed within 5-20 $\mathrm{min}$ at room temperature. The fluorescence intensity reached its highest value, remained constant for at least $150 \mathrm{~min}$, and then slowly decreased. Hence, all of the chelation reactions were carried out for $20 \mathrm{~min}$ at room temperature. All of the measurements were made at room temperature within $2 \mathrm{~h}$. Effect of the addition order of the reagents. The experimental results showed that different orders of addition of the components had little impact on both $F$ and $\Delta F$. Considering the enhancement of the fluorescence intensity of the system, we chose the following order for further study: DC, $\mathrm{Eu}^{3+}$, ATP, and buffer last.
Influence of the coexisting substance. A series experiments of coexisting substances had been carried out on the fluorescence of the DC-Eu ${ }^{3+}$-ATP system under the optimum condition. The concentrations of the coexisting substances approximate that of the human body fluid. Including mental ions, bases and proteins were also examined for interference. The criterion for interference was fixed at a $\pm 10 \%$ variation of the average fluorescence intensity, calculated for the established level of ATP. The experimental results are given in Table 1. From Table 1 it can be seen that most of the coexisting substances were found to show no influence.

\section{Analytical application}

Linearity range and detection limit of $D C$. Under the optimal experimental conditions, there was a good linear relationship between the fluorescence intensity and the concentration of ATP in the range of $1.00 \times 10^{-7}-2.00 \times 10^{-6} \mathrm{~mol} \mathrm{~L}^{-1}$ in the DC$\mathrm{Eu}^{3+}$-ATP system with a correlation coefficient $(r)$ of 0.99471 . The detection limit for the determination of DC was $4.07 \times 10^{-8}$ mol L ${ }^{-1}$. The standard deviation was 0.05 , obtained from a series of 11 reagent blanks.

Determination of ATP in injection and tablet forms. The developed method was applied to the determination of ATP in samples of injection and tablet forms. The results were given in Table 2. Injections and tablets were purchased from a drugstore. Two injections (one containing $20 \mathrm{mg}$ ) were directly diluted to $100 \mathrm{ml}$. Two tablets (one containing $20 \mathrm{mg}$ ) were added to $0.30 \mathrm{~g}$ of trichloroacetic acid, whisked and then filtrated with $0.45 \mu \mathrm{m}$ filter paper. The solution was diluted to $100 \mathrm{ml}$. All were diluted to a linear range, and then analyzed by the method mentioned above, using the standard calibration method. From Table 2, it can be seen that the developed method can be easily performed and affords good precision, and accuracy when applied to real samples.

\section{Conclusion}

A literature survey shows that $\beta$-diketonate ligands are suitable for efficient energy transfer from them to the $\mathrm{Eu}^{3+}$ ion, and for a high fluorescence quantum yield, a large Stoke shift, narrow emission bonds, and a long lifetime. They would thus avoid potential background fluorescence emission interference from a biological matrix. Doxycycline (DC) containing the $\beta$ diketonate configuration is a good ligand for $\mathrm{Eu}^{3+}$, and can strongly bind with $\mathrm{Eu}^{3+}$. This can be proved by the fluorescence emission spectra. After the addition of ATP into the DC-Eu ${ }^{3+}$ system, a light blue shift occurred to the maximal excitation wavelength, and the fluorescence intensity of the $\mathrm{Eu}^{3+}$ ion at 612 $\mathrm{nm}$ could be remarkably enhanced. This was a result from the formation of the DC $+\mathrm{ATP}+\mathrm{Eu}^{3+}$ complex.

The coordination number of $\mathrm{Eu}^{3+}$ in its complex is 8, but the molar ratio of $\mathrm{DC}$ to $\mathrm{Eu}^{3+}$ ions in this study was $\mathrm{DC}: \mathrm{Eu}^{3+}=3: 5$ in aqueous solution without ATP. Therefore, the coordination number of $\mathrm{Eu}^{3+}$ cannot be satisfied. $\mathrm{An}^{\mathrm{Eu}^{3+}}$ will coordinate with $\mathrm{H}_{2} \mathrm{O}$ to form the DC-Eu ${ }^{3+}-\left(\mathrm{O}-\mathrm{H}_{2}\right)_{\mathrm{n}}$ complex. DC-Eu ${ }^{3+}$ $\left(\mathrm{O}-\mathrm{H}_{2}\right)_{\mathrm{n}}$ have an excrescent positive charge, which can easily combine with the electronegative phosphate of ATP by electrostatic binding. When ATP is added into the DC-Eu ${ }^{3+}$ $\left(\mathrm{O}-\mathrm{H}_{2}\right)_{\mathrm{n}}$ complex, $\mathrm{O}$ of electronegative phosphate of ATP can replace $\left(\mathrm{O}-\mathrm{H}_{2}\right)_{\mathrm{n}}$ and bind to $\mathrm{Eu}^{3+}$, forming the $\mathrm{DC}-\mathrm{Eu}^{3+}-\mathrm{ATP}$ complex. The energy transfer from DC and ATP to the $\mathrm{Eu}^{3+}$ ion can more easily occur, and non-radioactive energy loss through the $\mathrm{O}-\mathrm{H}$ vibration of $\mathrm{H}_{2} \mathrm{O}$ in the original DC-Eu ${ }^{3+}$ complex can be greatly decreased. The fluorescence intensity of the DC- 
Table 2 Determination of ATP in injection and tablet samples $(n=5)$

\begin{tabular}{|c|c|c|c|c|c|c|}
\hline \multirow[b]{2}{*}{ ATP sample } & \multirow[b]{2}{*}{$\begin{array}{l}\text { Sample added } \\
\left(10^{-6} \mathrm{~mol} \mathrm{~L}^{-1}\right)\end{array}$} & \multicolumn{3}{|c|}{ Found } & \multirow{2}{*}{$\begin{array}{l}\text { Average } \\
\text { recovery, \% }\end{array}$} & \multirow[b]{2}{*}{ RSD, $\%$} \\
\hline & & $\begin{array}{l}\text { Single found/ } \\
10^{-6} \mathrm{~mol} \mathrm{~L}^{-1}\end{array}$ & $\begin{array}{l}\text { Average/ } \\
10^{-6} \mathrm{~mol} \mathrm{~L}^{-1}\end{array}$ & $\begin{array}{c}\text { Conversion of mark } \\
\text { value/mg unit }\end{array}$ & & \\
\hline $\mathrm{a}$ & 1.16 & 1.201 .221 .261 .211 .23 & 1.22 & 21.04 & 105.2 & 1.9 \\
\hline $\mathrm{b}$ & 1.16 & 1.051 .121 .191 .141 .14 & 1.13 & 19.48 & 97.4 & 1.6 \\
\hline $\mathrm{c}$ & 1.16 & 1.101 .091 .141 .131 .16 & 1.12 & 19.32 & 96.6 & 2.6 \\
\hline d & 1.16 & 1.111 .221 .201 .131 .23 & 1.18 & 20.34 & 101.7 & 4.4 \\
\hline e & 1.16 & 1.201 .211 .171 .151 .16 & 1.18 & 20.34 & 101.7 & 2.2 \\
\hline $\mathrm{f}$ & 1.06 & 1.050 .970 .960 .951 .00 & 0.99 & 18.68 & 93.4 & 4.1 \\
\hline $\mathrm{g}$ & 1.06 & 1.071 .061 .051 .061 .11 & 1.07 & 20.18 & 100.9 & 2.7 \\
\hline
\end{tabular}

a, Tianjin jiaozuo pharmaceutical Co., Ltd. (injection); b, Shanghai tongyong pharmaceutical Co., Ltd. (injection); c, Qilu pharmaceutical Co., Ltd. (injection); d, Xuzhou laien pharmaceutical Co., Ltd. (injection); e, Changzhou lanling pharmaceutical Co., Ltd. (injection); f, Shandong laiyang pharmaceutical Co., Ltd. (tablet); g, Fujian gutian pharmaceutical Co., Ltd. (tablet).

$\mathrm{Eu}^{3+}$-ATP system is in proportion to the concentration of ATP This method has been successfully applied to the determination of ATP in injection and tablet samples.

\section{Acknowledgements}

The authors are grateful for the National Natural Science Foundation of China for its financial support (Grant No. 20271043).

\section{References}

1. A. Lundin and A. Thore, Anal. Biochem., 1975, 66, 47.

2. P. E. Michel, S. M. Gautier-Sauvigne, and L. J. Blum, Anal. Chim. Acta, 1998, 360, 89.

3. M. T. Veciana-Nogues, M. Izquierdo-Pulido, and M. C.
Vidal-Carou, Food Chem., 1997, 59, 467.

4. F. Scheller and D. Pfeifer, Anal. Chim. Acta, 1980, 117, 383.

5. D. Compagnone and G. G. Guilbault, Anal. Chim. Acta, 1997, 340, 109.

6. K. Mosbach and B. Danielson, Biochim. Biophys. Acta, 1974, 364, 140.

7. P. Ronner, E. Friel, K. Czerniawski, and S. Frankle, Anal. Biochem., 1999, 275, 208.

8. A. R. Ribeiro, R. M. Santos, L. M. Rosario, and M. H. Gil, J. Biolumin. Chemilumin., 1998, 13, 371.

9. Y. Kawamoto, K. Shinozuka, M. Kunitomo, and J. Haginaka, Anal. Biochem., 1998, 262, 33.

10. C. Karatzaferi, A. De Haan, C. Offringa, and A. J. Sargeant, J. Chromatogr., B, 1999, 730, 183.

11. T. Sakakibara, S. Murakami, N. Eisaki, M. Nakajima, and K. Imai, Anal. Biochem., 1999, 268, 94. 